\title{
Synthesis, Characterization And Computational Studies Of Novel (E)-N-(3,4-Dimethoxybenzylidene)naphthalen-1-amine
}

\author{
Mariyam $^{1 *}$, B F Y Serli ${ }^{2}$ and N Adliani ${ }^{3}$ \\ ${ }^{1}$ Department of Chemistry, Faculty of Science, Institut Teknologi Sumatera \\ ${ }^{2}$ Department of Computational Science, Faculty of Science, Institut Teknologi Sumatera \\ ${ }^{3}$ Department of Pharmacy, Faculty of Science, Institut Teknologi Sumatera
}

\begin{abstract}
Novel (E)-N-(3,4-dimethoxybenzylidene)naphthalen-1-amine (DBNA) ligand has been synthesized by refluxing 1-naphthylamine and 3,4-dimethoxybenzaldehyde in methanolic solution for 5-6 hours. The obtained compound was characterized by UV-Vis, FT-IR and ${ }^{1} \mathrm{H}-$ NMR. All the spectral data confirmed the structure of the ligand.
\end{abstract}

\section{Introduction}

Heterocyclic compounds play important part in organic chemistry because of their specific structure and functions to respond many demands of biochemical systems. Heterocyclic is the majority of pharmaceuticals and biologically active compound[1]. Among heterocyclic compounds, Schiff base ligands derived from aromatic amines and aromatic aldehydes have received significant interest in the development of coordination chemistry[2] and wide range of applications[3]. Schiff base ligands are able to form coordination bond with many different metals and to stabilize them in various oxidation states[4].

Schiff base ligands and their transition metal complexes have been extensively explored as antimicrobial, antifungal, antituberculosis and anticancer agents. Schiff base metal complexes have promising material in clinical, analytical, industrial applications and organic synthesis[5][6]. However, efforts to further studies must be done to improve the functionality of Schiff base derivatives. Therefore, in this paper, we report the synthesis, characterization and computational studies of Schiff base ligand derived from aromatic amine (1-naphthylamine) and aromatic aldehyde (3,4-dimethoxybenzaldehyde).

\section{Materials and Method}

2.1. Materials

All chemicals used are analytical grade from Merck. 1-naphthylamine, 3,4-dimethoxybenzaldehyde, methanol and acetone.

\subsection{Instrumentation}

Electronic spectra were investigated by using Agilent spectrophotometer UV-Vis Cary 100. The IR spectra was performed by Fourier Transform Infrared (FTIR) Shimadzu IR prestige-21. 1H-NMR spectra were recorded using Agilent $500 \mathrm{MHz}$. Thermal analysis was recorded by TGA and DTA instrument (Exstar SII 7300 series). 
2.3 Synthesis of Ligand (E)-N-(3,4-dimethoxybenzylidene)naphthalen-1-amine Equimolar ratio of 1-naphthylamine $(0.859 \mathrm{~g}, 6 \mathrm{mmol})$ and 3,4-dimethoxybenzaldehyde $(0.997 \mathrm{~g}, 6$ mmol) were dissolved in methanol. The solution was refluxed for 5-6 hours at constant temperature about $60-70^{\circ} \mathrm{C}$. The reaction progress was monitored by thin layer chromatography. Purification of the obtained compound was done by washing the ligand with methanol. Methanol was added to the resulting compound for recrystallization to yield pure compound.

240, 279 and $317 \mathrm{~nm}$

Brown solid. Yield $=78.5 \%$. m.p $=129^{\circ} \mathrm{C}$. UV-Vis $(200-700 \mathrm{~nm}) ;(\lambda: \mathrm{nm}):(240 \mathrm{~nm})(279 \mathrm{~nm})(317 \mathrm{~nm})$. FT-IR (KBr, cm-1); 3043.67, $3001.24\left(v_{\mathrm{CH}-\mathrm{Ar}}\right): 2931.80\left(v_{\mathrm{C}-\mathrm{H}}\right): 2862.36\left(v_{\mathrm{O}-\mathrm{CH} 3}\right) 1627.92\left(v_{\mathrm{C}=\mathrm{N}}\right)$ : 1577.77, $1510.26\left(v_{\mathrm{C}=\mathrm{C}}\right) .{ }^{1} \mathrm{H}-\mathrm{NMR}\left(\mathrm{CDCl}_{3}\right), \mathrm{ppm}: \delta=4.03,3.97\left(\mathrm{O}-\mathrm{CH}_{3}\right), \delta=6.95-8.36$ (Ar-proton), $\delta=8.45(\mathrm{~N}=\mathrm{CH})$.
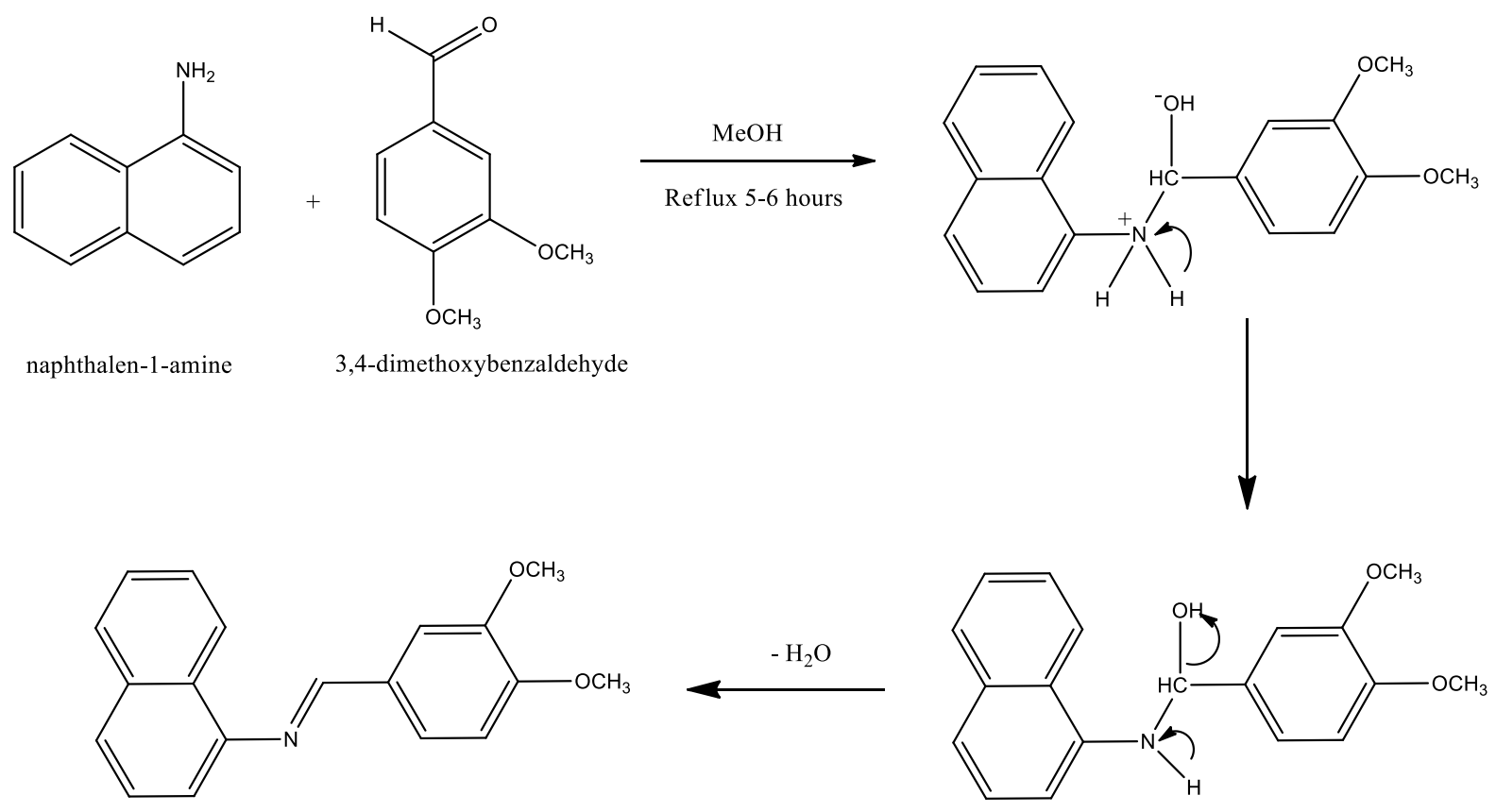

(E)-N-(3,4-dimethoxybenzylidene)naphthalen-1-amine

Scheme 1: The synthesis route of the ligand (DBNA)

2.4 Computational Method

Computational study towards DBNA has been done using GAMESS ${ }^{\odot}$ software to calculate HOMO and LUMO energy level. In this study, we use Slater Type Orbital Gaussian 3-21, under Density Functional Theory. For the Self-Consistent Field, Restricted Hartree Fock type has been applied with convergence criteria $10^{-5}$.

\section{Results and Discussions}

\section{UV-Vis Spectral Data}

The UV-Vis spectral data of DBNA ligand showed intense peaks at 240, 279 and $317 \mathrm{~nm}$. These intense peaks are assigned to $\mathrm{n}-\pi^{*}$ transitions for azomethine group (-N=CH-) and $\pi-\pi^{*}$ transitions of conjugated $\pi$-bonding systems in ligand (fig.1). 


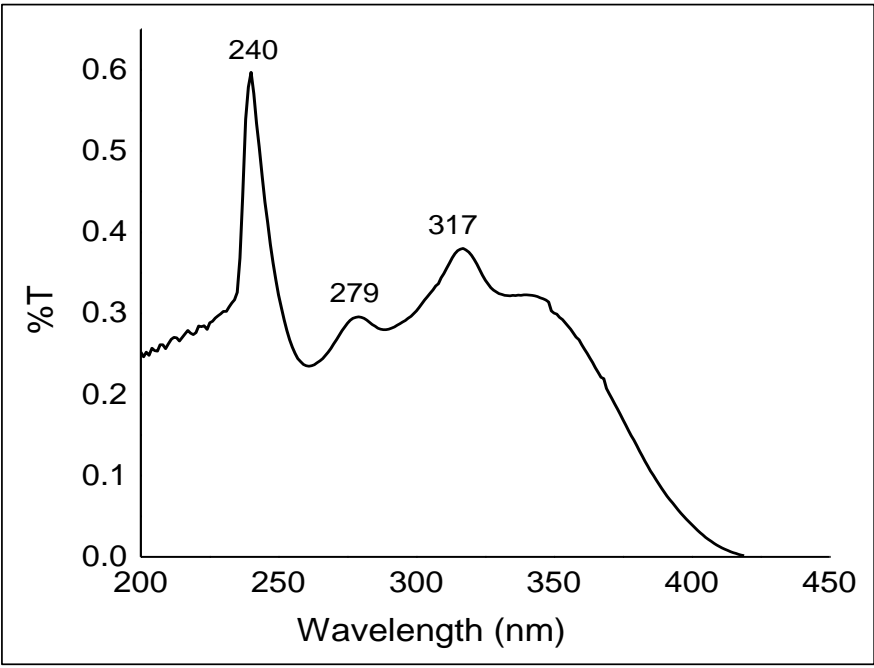

Fig.1 UV-Vis spectrum of DBNA ligand

\section{FTIR Spectral Data}

The FTIR spectrum of DBNA (fig. 2) showed stretching band at $1510.26 \mathrm{~cm}^{-1}$ and $1577.77 \mathrm{~cm}^{-1}$ which were assigned to the absorption of $\mathrm{C}=\mathrm{C}$ stretching for aromatic ring. The sharp peak at $1627.92 \mathrm{~cm}^{-1}$ was observed as $\mathrm{C}=\mathrm{N}$ stretching frequency in the azomethine group which indicated $\mathrm{NH}$ group from naphthylamine moeity was associated with $\mathrm{C}$ atom of benzaldehyde gave Schiff base formation. The two methoxy groups $\left(\mathrm{O}-\mathrm{CH}_{3}\right)$ in the ligand was observed at $2862.36 \mathrm{~cm}^{-1}$. While the aromatic ring moiety were assigned to the absorption band of $\mathrm{C}-\mathrm{H}$ alkyl stretching at $2931.8 \mathrm{~cm}^{-1}$ and $\mathrm{C}-\mathrm{C}$ aromatic stretching at 3001.24 and $3043.67 \mathrm{~cm}^{-1}$. The pattern of overtone bands in the region $2000-1850 \mathrm{~cm}^{-1}$ indicated of aromatic moiety in the ligand.

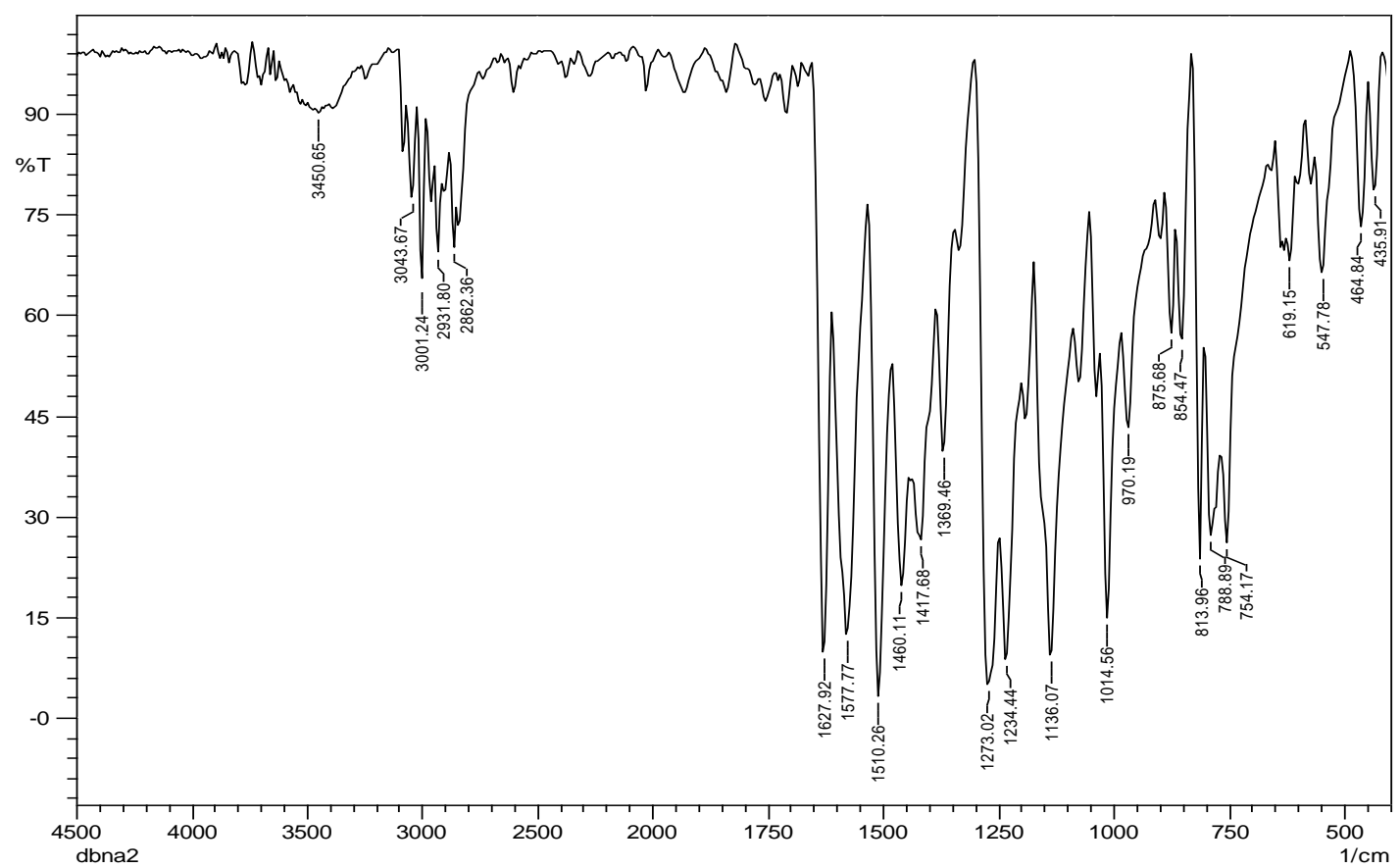

Fig 2. IR spectrum of DBNA ligand

\section{${ }^{1} \mathrm{H}$-NMR Spectral Data}

The ${ }^{1} \mathrm{H}-\mathrm{NMR}$ spectrum of DBNA was measured in $\mathrm{CDCl}_{3}$ solvent. The spectrum showed signal at $\delta 8.45 \mathrm{ppm}$ corresponded to the azomethine proton $(\mathrm{N}=\mathrm{CH})$ that bound between naphthalene and benzaldehyde moiety. The two signals at $\delta=3.97$ and $4.03 \mathrm{ppm}$ refer to methoxy groups (O-CH3) bound 
to the benzaldehyde moiety. Other signals in the region $\delta=6.95-8.36 \mathrm{ppm}$ could be attributed to the protons of aromatic rings of the ligand.

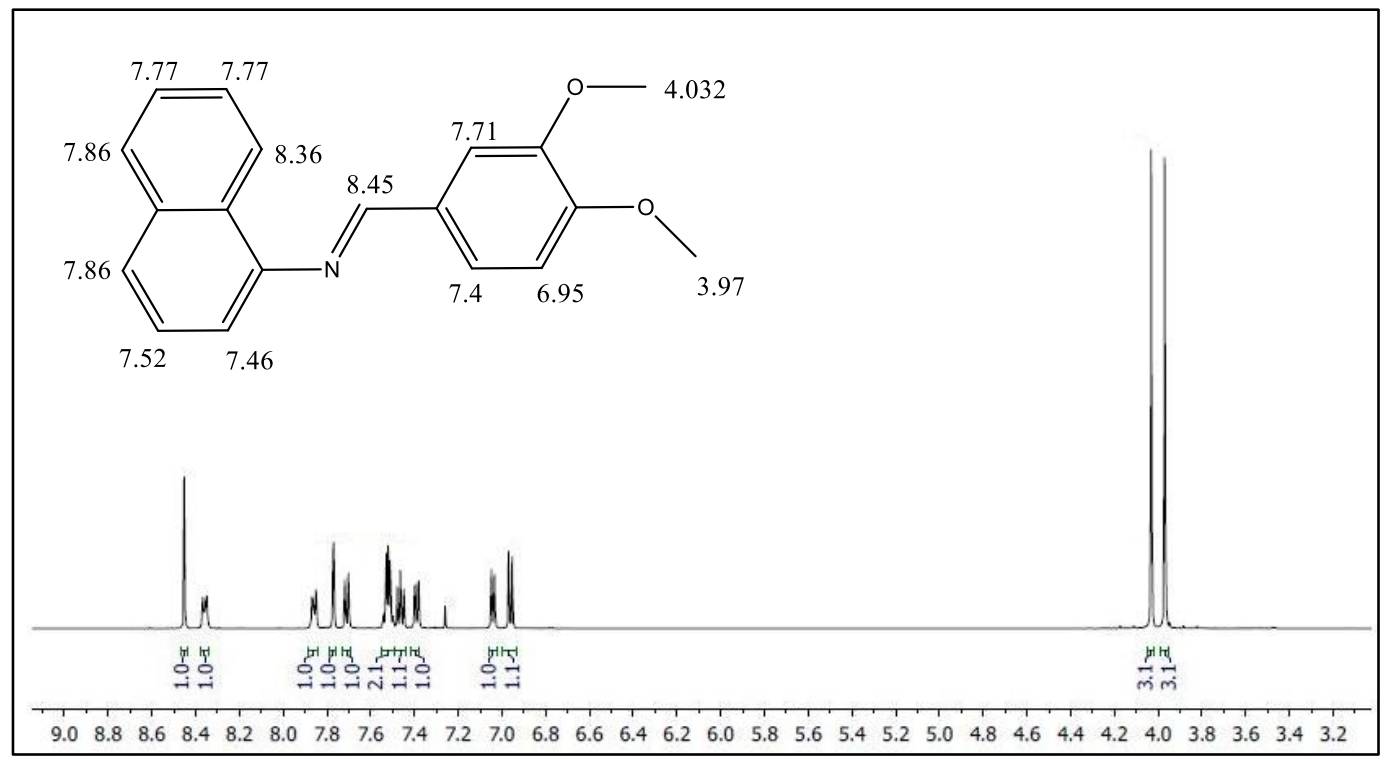

Fig 3. ${ }^{1} \mathrm{H}-\mathrm{NMR}$ Spectrum of DBNA ligand

\section{Computational Studies}

HOMO and LUMO energy level of DBNA molecul has been calculated for any needs of complex's synthesis. This calculation will be able to be used in the future to predict properties of the ligand and also depict how the complex can be used in various aspect. The frontier molecular orbital energies (i.e., $\mathrm{E}_{\text {номо }}$ and $\left.\mathrm{E}_{\mathrm{LUMO}}\right)$ are significant parameters for the prediction of the reactivity and stability of a chemical compound. The $\mathrm{E}_{\text {номо }}$ is often associated with the electron donating ability (Ionization energy) of a molecule. The E EUMO indicates the ability of the molecule to accept electrons (Electron affinity). By comparing HOMO and LUMO energy level from 2 molecules can indicates the tendency of the molecules to donor or to accept electrons. From the calculation, the HOMO energy level of DBNA molecules as represent in fig.4 is $-5.27360808 \mathrm{eV}$, while the LUMO energy level (fig.5) is 4.43821196 $\mathrm{eV}$.

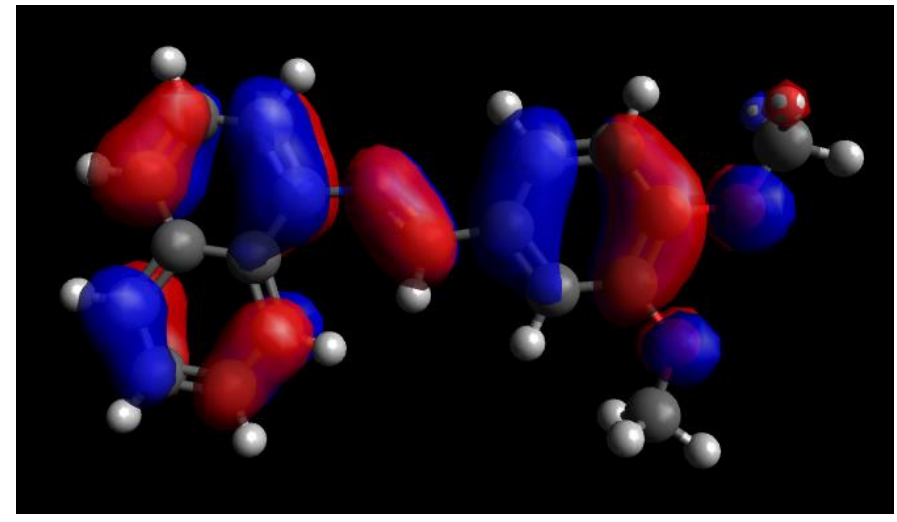

Fig.4 HOMO surface of DBNA 


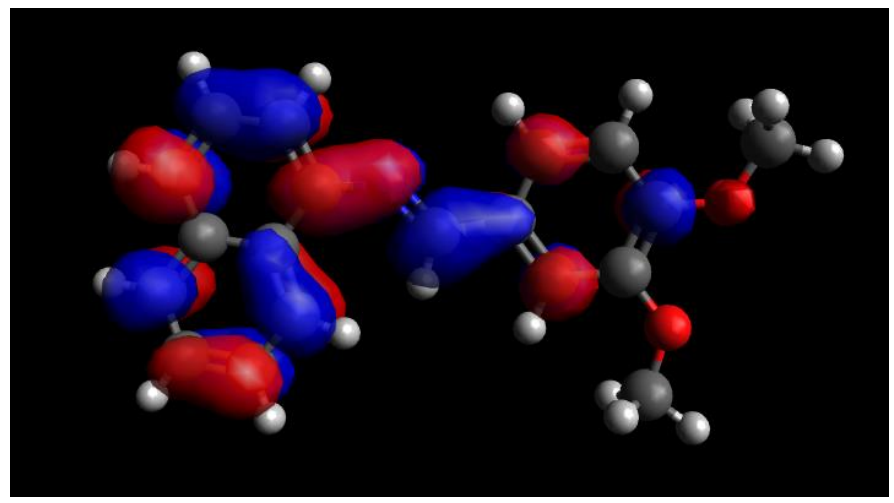

Fig.5 LUMO surface of DBNA

\section{Conclusion}

Novel (E)-N-(3,4-dimethoxybenzylidene)naphthalen-1-amine have been synthesized and characterized by various spectroanalytical method, they are UV-Vis, FT-IR and ${ }^{1} \mathrm{H}-\mathrm{NMR}$. Spectroanalytical studies revealed the correct structure of the molecule as expected. FT-IR spectral data showed particular bonding which correspond to $\mathrm{C}=\mathrm{C}, \mathrm{C}=\mathrm{N}, \mathrm{O}-\mathrm{CH}_{3}, \mathrm{C}-\mathrm{C}$ aromatic and $\mathrm{C}-\mathrm{H}$ alkyl. ${ }^{1} \mathrm{H}-$ NMR also depict azomethine proton $(\mathrm{N}=\mathrm{CH})$, methoxy group and protons of aromatic ring in the ligand. Computational studied has been done as an initial step to prove the tendency of electron donor-acceptor of the ligand.

\section{Reference}

[1] C. S. D. Ranjithreddy Palreddy, Jaheer Mohmed, Nagula Narsimha, Boinala Aparna, Mariyam, "Synthesis, characterization and biological activity of 2-acetylpyridine- ?naphthoxyacetylhydrazone its metal complexes," J. Mater. Sci. Chem. Eng., vol. 3, no. October, pp. 45-59, 2015.

[2] R. S. Joseyphus, C. Shiju, J. Joseph, C. J. Dhanaraj, and D. Arish, "Spectrochimica Acta Part A : Molecular and Biomolecular Spectroscopy Synthesis and characterization of metal complexes of Schiff base ligand derived from imidazole-2-carboxaldehyde and 4aminoantipyrine," Spectrochim. ACTA PART A Mol. Biomol. Spectrosc., vol. 133, pp. 149155, 2014.

[3] X. Ouyang, B. Fei, T. Okamura, W. Sun, Ã. W. Tang, and N. Ueyama, "Synthesis, Crystal Structure and Superoxide Dismutase ( SOD ) Activity of Novel Seven-Coordinated Manganese ( II ) Complex with Multidentate Di-Schiff Base Ligands," vol. 85, no. Ii, pp. 3-4, 2002.

[4] O. B. Ibrahim, M. A. Mohamed, and M. S. Refat, "Nano Sized Schiff Base Complexes with Mn ( II ), Co ( II ), Cu ( II ), Ni ( II ) and Zn ( II ) Metals : Synthesis, Spectroscopic and Medicinal Studies," vol. 2, no. 2, pp. 108-121, 2014.

[5] S. R. Bakir, "Synthesis, Spectral Studies, and Theoretical Treatment of some New Metal Complexes with Tridentate Ligand ( Schiff and Mannich Base ) Abstract : Introduction: Materials and Methods :," vol. 13, no. 2, 2016.

[6] Foziah Ali Al-Saif et al., "Chemistry in Drug Discovery \& Designing," vol. 7, p. 4172, 2018.

\section{Acknowledgments}

The authors gratefully thank Institut Teknologi Sumatera and Department of Chemistry for providing facilities and financial support. 